House rejected amendments seeking to delete other weapons systems. A request for $\$ 19$ million with which to begin deploying antisatellite weapons (ASATs) was approved despite warnings from Representative George Brown (Democrat, California) that the eventual cost would reach tens of thousands of millions and would all but rule out the possibility of a verifiable ban on ASATs. The US Air Force is planning a test this summer of ASAT, which is a nonexplosive projectile launched from an F-15 fighter. Research and development costs of the project have already reached $\$ 1,000$ million. Funds for the B-1 bomber and for the army's controversial computer-controlled antiaircraft gun, known as DIVAD or the "Sergent York", were likewise approved. The contentious question of funds for deployment of the MX missile will be taken up after the House returns from its 4 July recess.
Stephen Budiansky
Nixon ordered a unilateral halt to production. Unlike the proposed binary weapons, which contain two relatively benign chemicals that are mixed to produce the lethal agent, the older weapons contain live nerve agent.

The vote to delete the $\$ 115$ million requested to begin production came amid disclosures of serious design flaws in one of the proposed weapons, the "Big Eye" bomb. Last month, the US Army conceded that the bombs could explode prematurely, and dropped $\$ 43$ million from the production request. The remaining $\$ 115$ million would have gone towards production of 155-mm shells but would also apparently have been used to build production lines for the Big Eye and even to begin manufacture of the bomb casings.

According to Representative Ed Bethune (Republican, Arkansas), who sponsored the amendment to delete production funding along with Representative Clement Zablocki (Democrat, Wisconsin), Big Eye had been designed for a high altitude drop. As originally conceived, the two chemicals in the bomb would be mixed before release. Bethune said that the army realized only recently that a high-altitude attack was out of the question because the aircraft would be detected by radar, and when they began testing at low altitudes, they discovered that the high temperatures could cause sufficent gas pressure within the bomb to rupture it.

The administration engaged in a heavy lobbying effort in support of its request for funds. Proponents, backed by letters from the Department of Defense and from Secretary of State George Shultz, argued that progress on a treaty banning possession of chemical weapons could only be achieved by demonstrating US resolve to build the new weapons. The lobbying effort even included the screening of a film, produced by the army only two weeks ago, of a successful test of Big Eye. During debate on the amendment, Bethune heatedly countered that the test involved dropping the bomb from 6,000 feet and starting the mixture only after the bomb was dropped. Bethune said that 15 to 20 seconds are needed for the reaction totally impractical for low-altitude attacks. And he said "they would be shot down in a minute" flying at 6,000 feet if it were a real approximately $\$ 900$ million that the istration had requested for $c$ defence and research on chemical weapons. Nor did it appear to be indicative of general opposition to the Reagan defence programme. By wide margins, the

\title{
Spina bifida
}

\section{MRC folate trials to start at last}

THE Medical Research Council's (MRC's) clinical trials of folic acid for preventing neural tube defects in newborn babies are ready to start within weeks, but the council is waiting for final approval of its plans from the Scottish Home Health Departments.

The trials are controversial because they involve giving placebos to a double-blind control group comprising pregnant women who have already given birth to a child with a neural tube defect (NTD) such as spina bifida. There have been fears that if any of the placebo group gave birth to a second child with NTD they could bring a court action in the event of folic acid proving effective. Scottish law in this area is different from English law, and the Scottish authorities are looking hard at the wording of the advice to be given to potential volunteers. Dr Nicholas Wald, who is to coordinate the trials, says the information being provided is "pretty comprehensive".

Earlier this year, Professor J.A. Davis, who was chairman of the trials steering committee, resigned because of reservations about the trials' feasibility. Up to 4,000 volunteers may be required for an adequate assessment of folic acid, and there are doubts about whether this total can be reached in a five-year trial, partly because of adverse publicity. All of the volunteers will already have given birth to one NTD child. Questions were asked in parliament after MRC announced its decision to conduct the trials, which are to take place in the United Kingdom, Australia and Israel.

Previous studies suggesting that folic acid taken in early pregnancy may prevent NTD have the weakness that the study groups were self-selected. In addition, the effect of folic acid was not clearly distinguished from that of other vitamins (see
Nature 300, 396; 1982). MRC has taken the view that the matter can be settled only by a trial with women allocated at random to treatment and control groups. A committee has been set up to monitor the trial, which can be called off if early results show a clear effect.

The Helsinki Code, adopted by the World Medical Association in 1975, re-

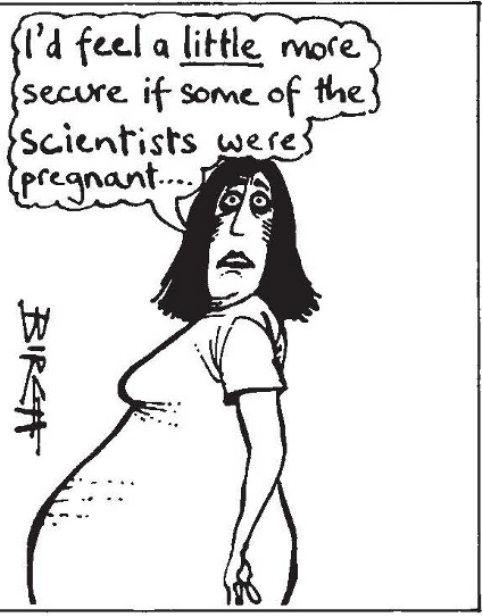

quires that the interests of individual pa. tients should always be put before possible future benefits to humanity. MRC's own ethical guidelines appear to support the principle, and the new chairman of the trials' steering committee, Professor Geoffrey Rose, says the trial protocol satisfies this condition. The argument seems to hang on the possibility that folic acid in the high doses to be used in the trials could cause harm, either directly or by raising false hopes about an expensive but worthless treatment. Professor Rose has no comment to make on the Scottish authorities' delay, other than to suggest that it might be a consequence of the recent general election. 